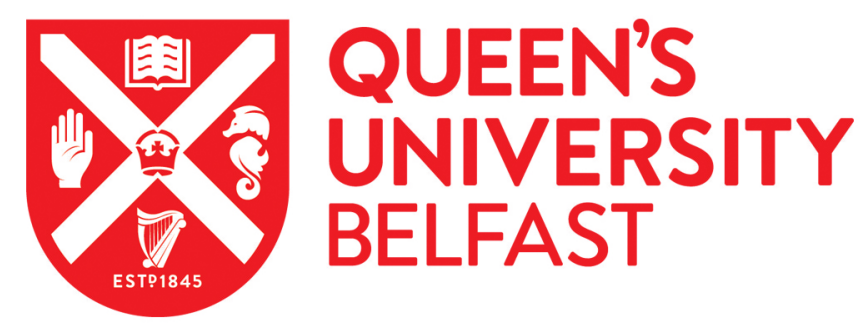

\title{
Ultrashort Cationic Naphthalene-Derived Self-Assembled Peptides as Antimicrobial Nanomaterials
}

\author{
Laverty, G., McCloskey, A. P., Gilmore, B. F., Jones, D. S., Zhou, J., \& Xu, B. (2014). Ultrashort Cationic \\ Naphthalene-Derived Self-Assembled Peptides as Antimicrobial Nanomaterials. Biomacromolecules, 15(9), \\ 3429. https://doi.org/10.1021/bm500981y
}

\section{Published in: \\ Biomacromolecules}

\section{Document Version:}

Peer reviewed version

Queen's University Belfast - Research Portal:

Link to publication record in Queen's University Belfast Research Portal

\section{Publisher rights}

This document is the Accepted Manuscript version of a Published Work that appeared in final form in Biomacromolecules , copyright $\odot 2014$ American Chemical Society after peer review and technical editing by the publisher. To access the final edited and published work seehttp://pubs.acs.org/doi/abs/10.1021/bm500981y

\section{General rights}

Copyright for the publications made accessible via the Queen's University Belfast Research Portal is retained by the author(s) and / or other copyright owners and it is a condition of accessing these publications that users recognise and abide by the legal requirements associated with these rights.

Take down policy

The Research Portal is Queen's institutional repository that provides access to Queen's research output. Every effort has been made to ensure that content in the Research Portal does not infringe any person's rights, or applicable UK laws. If you discover content in the Research Portal that you believe breaches copyright or violates any law, please contact openaccess@qub.ac.uk. 


\title{
Ultrashort Cationic Naphthalene derived Self-
}

\section{assembled Peptides as Antimicrobial Nanomaterials}

\author{
Garry Laverty ${ }^{* 1}$, Alice P. McCloskey ${ }^{1, \ddagger}$, Brendan F. Gilmore, ${ }^{1, \ddagger}$, David S. Jones ${ }^{1, \ddagger}$, Jie Zhou ${ }^{2, \ddagger}$, \\ Bing $X u^{2, \ddagger}$. \\ ${ }^{1}$ School of Pharmacy, Queens University Belfast, 97 Lisburn Road, Belfast, BT9 7BL, UK. \\ ${ }^{2}$ Department of Chemistry, Brandeis University, 415 South St., Waltham, USA
}

KEYWORDS

Antimicrobial, Biomaterial, Bacteria, Infection, Peptide, Self-assembly.

\begin{abstract}
Self-assembling dipeptides conjugated to naphthalene show considerable promise as nanomaterial structures, biomaterials and drug delivery devices. Biomaterial infections are responsible for high rates of patient mortality and morbidity. The presence of biofilm bacteria, which thrive on implant surfaces, are a huge burden on healthcare budgets as they are highly resistant to current therapeutic strategies. Ultrashort cationic self-assembled peptides represent a highly innovative and cost-
\end{abstract}


effective strategy to form antibacterial nanomaterials. Lysine conjugated variants display the greatest potency with $2 \% \mathrm{w} / \mathrm{v}$ NapFFKK hydrogels significantly reducing viable Staphylococcus epidermidis biofilm by 94\%. Reducing the size of the R-group methylene chain on cationic moieties resulted in reduction of antibiofilm activity. The primary amine of the protruding Rgroup tail may not be as readily available to interact with negatively charged bacterial membranes. Cryo-SEM, FTIR, CD spectroscopy and oscillatory rheology provided evidence of supramolecular hydrogel formation at physiological $\mathrm{pH}(\mathrm{pH}$ 7.4). Cytotoxicity assays against murine fibroblast (NCTC 929) cell lines confirmed the gels possessed reduced cytotoxicity relative to bacterial cells, with limited hemolysis upon exposure to equine erythrocytes. The results presented in this paper highlight the significant potential of ultrashort cationic naphthalene peptides as future biomaterials.

Introduction

The increasing demand for biomaterials to replace normal physiological functions of the human body is largely attributed to an increase in life expectancy and advancement in modern healthcare and drug therapy. ${ }^{1}$ The biomaterial revolution has led to increased interest in the development of implants, biosensors, tissue scaffolds and wound dressings for medical applications. ${ }^{2-5}$

Hydrogels represent one of the most promising materials utilized in this field by mimicking the extracellular matrix of soft tissue, possessing key properties such as: biocompatibility; high water absorptivity and retention of three-dimensional architectures. ${ }^{6}$ However, one key limitation of unmodified hydrogels, for example poly (2-hydroxyethyl methacrylate) polymers, is their inability to resist infection by pathogenic microorganisms. ${ }^{7}$ The hydrogel surface provides an optimum 
structure for microbial attachment and the production of a highly resistant biofilm phenotype that displays 10-1000 times the resistance to standard antimicrobial regimens, when compared to freefloating planktonic forms. ${ }^{8}$ Medical device infections can be attributed to an increase in healthcare costs, patient morbidity, hospital stay and mortality. ${ }^{9}$

Self-assembled peptide hydrogels and their nanostructures have attracted interest for use as biomaterials and drug delivery vehicles. ${ }^{10,11}$ Of greatest potential clinically are the ultrashort aromatic dipeptide variants that display similar gelation properties to larger $\beta$-sheets and turns; $\alpha$ helices and coiled coils; and peptide amphiphiles but at a reduced cost and ease of synthesis. ${ }^{12}$ Ultrashort dipeptide gelators often consist of two phenylalanine building blocks conjugated to a molecule of high aromaticity, such as naphthalene (Nap) or 9-fluorenylmethoxycarbonyl (Fmoc). ${ }^{13,14}$ The presence of increased aromaticity confers improved structural integrity and superior gel strength to the molecule via $\pi-\pi$ interactions. Other intermolecular interactions, such as hydrogen bonding and van der Waal's interactions, provided by the peptide backbone, are also vital to ensuring the structural integrity of such gels. Diphenylalanine is the shortest structural recognition motif for the naturally occurring $\beta$-amyloid polypeptide, implicated in the formation of fibrous plaques in Alzheimer's. Researchers have harnessed the properties of aromatic groups for development of a range of diverse, short, nanomaterial structures in medical and technological research. ${ }^{15-17}$

The peptide primary structure possesses several key properties making them an ideal biomaterial platform. These include: availability of moieties for functionalization; chemical versatility; biocompatibility; biodegradability and minimal immunogenicity. ${ }^{18}$ Peptides have also been shown to be antimicrobial, existing as defensive weapons against infection throughout nature. Antimicrobial activity is conferred by an optimal hydrophobic: charge balance that exists within 
the peptide primary structure. ${ }^{19}$ Similarly the hydrophobic: hydrophilic balance governs gelation and self-assembly of peptides. ${ }^{20}$ Ultrashort variants exist displaying broad antimicrobial activity within a minimum peptide pharmacophore with hydrophobic bulk provided by lipophilic molecules such as fatty acids. ${ }^{21}$ The presence of cationic amino acids allows increased selectivity for negatively charged bacterial membranes rather than neutrally charged phospholipid bilayers.

In this report we outline the synthesis and characterization of a group of ultrashort aromatic peptide molecules, which self-assemble into inherently antimicrobial hydrogel nanostructures at physiological $\mathrm{pH}$ and have the potential to be utilized as future antimicrobial biomaterials.

\section{Experimental Section}

\section{Materials}

Fmoc and Boc protected amino acids and Wang resin (mesh size 100-200, $0.65 \mathrm{mmol} / \mathrm{g}$ ) were obtained from Novabiochem, Merck KGaA (Darmstadt, Germany). Cell viability reagent alamarBlue ${ }^{\circledR}$ was purchased from AbD Serotec (Oxford, UK). 37 \% Hydrochloric acid (HCl), Acetonitrile (HPLC grade, $\geq 99.93 \%$ ), 2-Naphthaleneacetic acid ( $>99 \%$ purity), Whatman ${ }^{\circledR} \mathrm{pH}$ indicator paper ( $\mathrm{pH}$ 0-14) and hydroxyl propyl methyl cellulose (HPMC) were obtained from Sigma-Aldrich (Dorset, UK ). Sterile Nunc ${ }^{\mathrm{TM}}$ 96-well microtitre plates and sodium hydroxide $(\mathrm{NaOH}) \geq 99.0 \%$ pellets were purchased from VWR International (Leicestershire, UK). NCTC Clone 929 (ATCC CCL 1) murine fibroblast subcutaneous connective tissue cells, Staphylococcus epidermidis (ATCC 35984), Staphylococcus aureus (ATCC 29213), Pseudomonas aeruginosa (PAO1) and Escherichia coli (NCTC 11303) were sourced from LGC Standards (London, UK). 
Fresh defibrinated equine erythrocytes were purchased from Laboratory Supplies \& Instruments Ltd (Antrim, UK).

Methods

Peptide Synthesis and Characterization

All peptides (Figure 1, NapFF, NapFFKK, NapFFFKK, NapFFOO, NapFFK'K') were synthesized following standard Fmoc solid phase protocols on Wang resin, using a manual nitrogen bubbler apparatus. Peptide elongation was effected using standard HBTU coupling chemistry in dimethylformamide (DMF) solvent with four-fold molar excess of diisopropyl ethylamine (DIEA) in DMF and a three-fold molar excess of each Fmoc-protected amino acid or naphthalene acetic acid. Boc-Lysine(Fmoc)-OH was used to synthesize the epsilon $(\varepsilon)$ variant NapFFK'K'. All peptides were cleaved from the resin, to form carboxylic acid terminated peptides, using 95\% trifluoroacetic acid (TFA), 2.5\% triisopropylsilane and 2.5\% thioanisole (3 hours, room temperature), and precipitated using cold $\left(-20^{\circ} \mathrm{C}\right)$ diethyl ether. The identity of each peptide was confirmed by electrospray mass spectroscopy (Thermo Finnigan LCQ Deca ion trap) and ${ }^{1} \mathrm{H}$ Nuclear Magnetic Resonance $\left({ }^{1} \mathrm{H}\right.$ NMR) analysis (Varian Unity Inova 400 spectrometer) in $\mathrm{C}_{2} \mathrm{D}_{6} \mathrm{OS}\left(\mathrm{d}_{6}\right.$-DMSO) (Figures S1-S5). Peptide purity was analyzed by RP-HPLC using an Agilent 1260 Infinity system, fitted with a Gemini C18, $250 \mathrm{~mm}$ x $4.6 \mathrm{~mm}$ column, a 2-60\% acetonitrile gradient [30min] in $0.05 \%$ TFA-water at a flow rate of $1.5 \mathrm{~mL} / \mathrm{min}$. All peptides were found to have $>95 \%$ purity. 

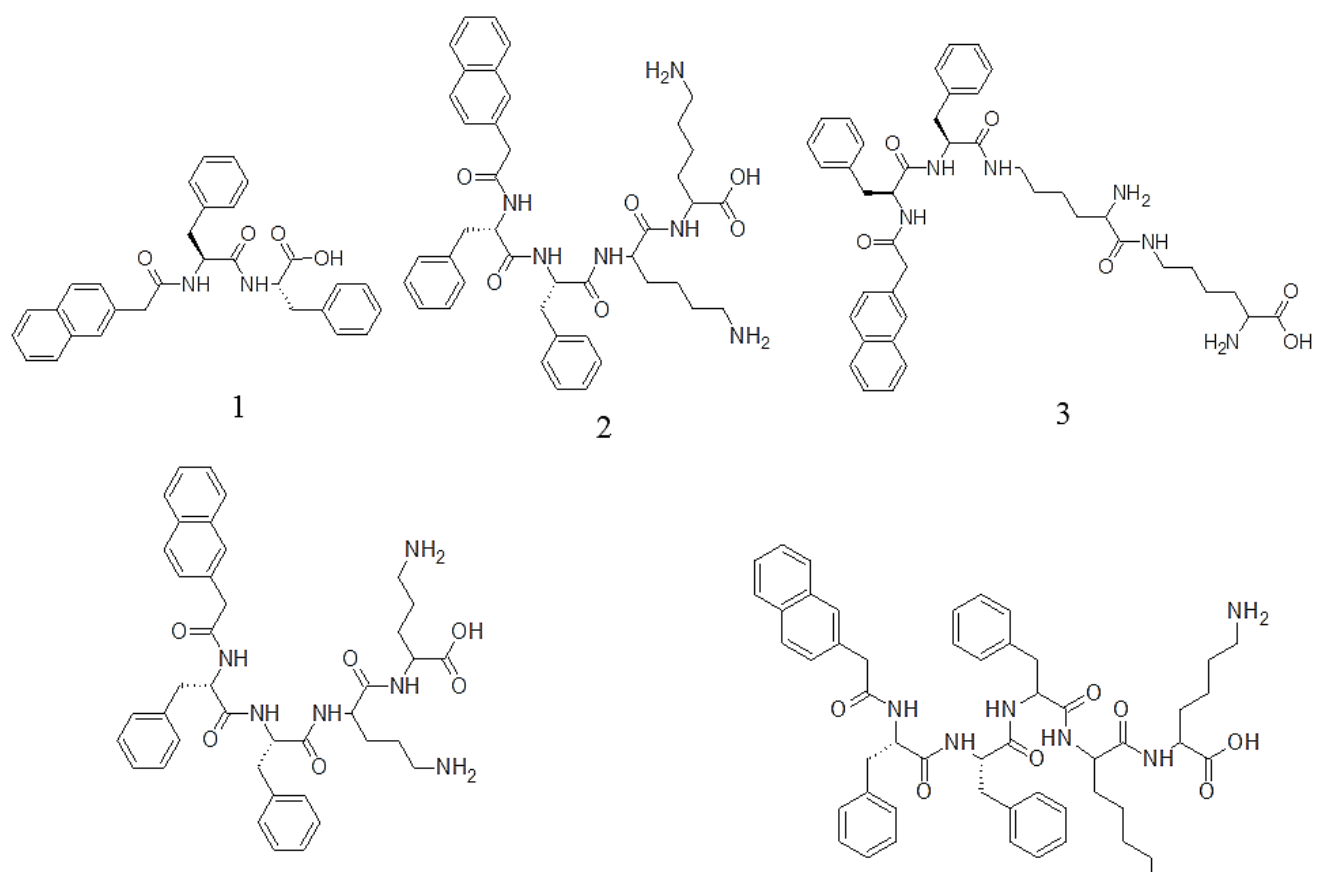

4

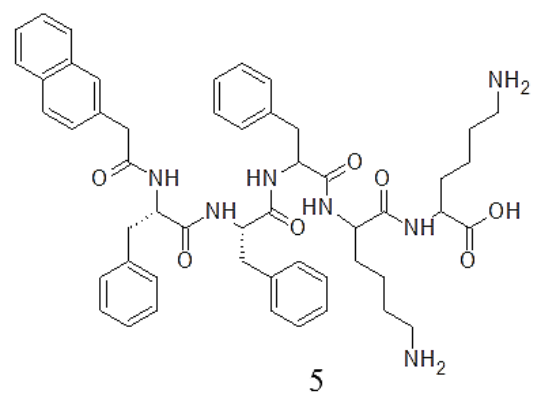

Figure 1. Chemical structures of the naphthalene peptide derivatives investigated. 1) NapFF, 2) NapFFKK, 3) NapFFK’K', 4) NapFFOO, 5) NapFFFKK

\section{Peptide Gelation}

Peptides were prepared and tested for gelation characteristics at concentrations of 2.0, 1.5, 1.0 and $0.5 \% \mathrm{w} / \mathrm{v}$ as previously outlined. ${ }^{13}$ Peptides were initially suspended in $200 \mu \mathrm{L}$ sterile deionized water. All peptides possessed a terminal carboxylic acid moiety. Therefore increasing the $\mathrm{pH}$ of the solution to $\mathrm{pH} 9$, via titration with $1 \mathrm{M} \mathrm{NaOH}$, resulted in deprotonation of the terminal species and full dissolution. Protonation of the terminal carboxylic acid via subsequent titration with $0.5 \mathrm{M} \mathrm{HCl}$ to $\mathrm{pH}$ 6-7 resulted in the formation of a homogenous gel at concentrations above the minimum gelation concentration for the peptide. $\mathrm{pH}$ was verified using Whatman $\mathrm{pH}$ 
paper. Gels were allowed to develop for 24 hours. Self-assembly and the formation of a selfsupporting gel was verified through the use of an inversion assay as previously described. ${ }^{22}$ Gels and solutions were differentiated based on flow characteristics with solutions demonstrating flow properties and gels remaining suspended.

Cryo-Scanning Electron Microscopy (Cryo-SEM)

Samples were freshly prepared via $\mathrm{pH}$ induction as outlined and analyzed for 3D fibrous morphologies. Cryo-SEM images were collected by high vacuum freeze-drying using a Hitachi Analytical Benchtop SEM TM3030 (Hitachi High-Technologies Europe, Berkshire, UK) with Deben Cool Stage (Deben, Suffolk, UK), using a method similar to that of Pogorelov and colleagues. ${ }^{23}$ Vacuum lyophilization was applied at $2{ }^{\circ} \mathrm{C}$ and images obtained at $-10{ }^{\circ} \mathrm{C}$, over a range of magnifications $(15 \mathrm{x}-30,000 \mathrm{x})$ and $15 \mathrm{kV}$ accelerating voltage.

\section{Transmission electron microscopy (TEM)}

TEM was performed using a FEI Morgagni 268 transmission electron microscope (FEI electronics, Burlington, Massachusetts, USA) and a negative staining technique. ${ }^{24} 400$ mesh copper grids were coated with continuous thick carbon film $(\sim 35 \mathrm{~nm})$ having been previously glow discharged to increase their hydrophilicity. $4 \mu \mathrm{L}$ samples were placed on the grid and rinsed three times with doubled distilled water. The grid was stained three times by a $2 \% \mathrm{w} / \mathrm{v}$ solution of uranyl acetate. Excess stain solution from the edge of the grid was removed using filter paper. Grids were allowed to air dry before immediate examination. 
Fourier Transform Infrared Spectroscopy (FTIR)

Hydrogel samples (2-0.5\% w/v) were prepared as described previously but with $\mathrm{D}_{2} \mathrm{O}$ replacing water. ${ }^{25}$ Prepared $\mathrm{D}_{2} \mathrm{O}$ containing hydrogels were sandwiched between two $\mathrm{CaF}_{2} 25 \mathrm{~mm}^{2}$ discs (0.05 mm spacer). FTIR spectra were obtained using a Jasco 4000 series FTIR spectrometer (Jasco Inc. Tokyo, Japan), between the wavelengths $4000-400 \mathrm{~cm}^{-1}$ with resolution $2 \mathrm{~cm}^{-1}$ and an average of 128 scans. The spectrum of deuterated water was used as a background and subtracted from all spectra.

Circular Dichroism (CD)

CD was performed using a Jasco J815 Spectropolarimeter and quartz cuvette $1 \mathrm{~mm}$ path length, with $1 \mathrm{~s}$ integrations, 1 accumulation and a step size of $1 \mathrm{~nm}$ with a band width of $1 \mathrm{~nm}$ over a range of wavelengths from 180 to $300 \mathrm{~nm}$ at $25{ }^{\circ} \mathrm{C}$. Peptide samples were prepared 24 hours previously to allow for hydrogelation. Measurements were repeated three times and mean value plotted. Control samples (sterile distilled water, $1 \mathrm{M} \mathrm{NaOH}, 0.5 \mathrm{M} \mathrm{HCl}, \mathrm{pH}$ 7.4) did not display any signal.

Oscillatory Rheology

The viscoelastic properties of the samples were determined using oscillatory rheology performed on a TA AR1500 rheometer at $25^{\circ} \mathrm{C}$. A $20 \mathrm{~mm}$ steel parallel plate was employed with a set gap of $500 \mu \mathrm{m}$. $400 \mu \mathrm{L}$ samples were applied to the plate using a pipetman. An oscillatory stress sweep was performed to determine the linear viscoelastic region (LVR) of each sample. This region, which is determined according to a superposition principle, is the area where stress is 
directly proportional to strain. There is a linear relationship between the two variables. Following this, an appropriate stress within the LVR was selected and a frequency sweep was performed at a range of $1-10 \mathrm{~Hz}$ with the selected stress remaining constant for each sample. Three distinct replicates for each sample were obtained and the storage modulus (G') and loss modulus (G') determined.

Biofilm Susceptibility Assay

All microbial strains tested: Staphylococcus epidermidis (ATCC 35984); Staphylococcus aureus (ATCC 29213); Pseudomonas aeruginosa (PAO1) and Escherichia coli (NCTC 11303) were stored at $-70{ }^{\circ} \mathrm{C}$ in Microbank vials (Pro-Lab Diagnostics, Cheshire, UK), and subcultured separately in Müller Hinton Broth (MHB) for 24 hours at $37^{\circ} \mathrm{C}$ before testing. Upon visual confirmation of growth the inoculum was taken and adjusted to optical density 0.3 at $550 \mathrm{~nm}$ in Quarter Strength Ringers Solution (QSRS), equivalent to $1 \times 10^{8}$ colony forming units per milliter (CFU/mL). This suspension was further diluted in MHB (1 in 50) and dispensed aseptically in $100 \mu \mathrm{L}$ aliquots to each well of the microtitre plate, corresponding to $2 \times 10^{6} \mathrm{CFU} / \mathrm{mL}$. Biofilms were formed on the surface of the well under shear stress provided by a Gallenkamp gyrorotary incubator at $37^{\circ} \mathrm{C}$. After an inoculation period of 24 hours cultures were decanted and the plates irrigated thrice with $200 \mu \mathrm{L}$ of sterile autoclaved $0.9 \% \mathrm{w} / \mathrm{v}$ sodium chloride $(\mathrm{NaCl})$ in each well. Washed plates were tapped gently upside down on a sterile paper towel to remove residual wash. The prepared biofilm was treated for evaluation of viability using alamarBlue ${ }^{\circledR}$ in a method similar to that used by Pettit. ${ }^{26} 100 \mu \mathrm{L}$ of 2.0 1.5, 1.0 and 0.5\% w/v NapFF, NapFFKK, NapFFFKK, NapFFOO and NapFFK'K' were pipetted into separate wells of the microtitre plate and biofilms assessed for reduction in viability after 24 hours exposure. Gels were removed from the microtitre 
plates by three rinses of each well with $\mathrm{NaCl}$. A range (3-0.5\% w/v) of HPMC gels (see supplementary data, Figure S21) were used as a standard non antimicrobial hydrogel comparator to ensure removal of gels did not remove significant quantity of biofilm bacteria. HPMC has previously been shown to possess no significant antimicrobial activity. ${ }^{27}$ HPMC displayed no significant reduction of viable biofilm compared to positive controls (no gel), thus ensuring the validity of the assay and methods employed. The viability of established biofilms is assessed by re-charging wells with $100 \mu \mathrm{L}$ of MHB containing 20\% v/v alamarBlue ${ }^{\circledR}$, incubating the plate at $37{ }^{\circ} \mathrm{C}$ for two hours to allow development, followed by spectrophotometric measurement of absorbance at a wavelength of $570 \mathrm{~nm}$ (Tecan Sunrise ${ }^{\circledR}$ plate reader). AlamarBlue ${ }^{\circledR}$ contains resazurin, a redox indicator which is reduced by the metabolic activity of viable microbial cells to develop into pink fluorescent resorfurin. Positive control (100\% microbicidal effect) corresponds to blank wells (no bacterial biofilm) treated with 70\% ethanol (added, removed and allowed to dry) immediately prior to the addition of $20 \% \mathrm{v} / \mathrm{v}$ alamarBlue ${ }^{\circledR}$. Eight replicates were performed at each concentration. Reduction in viability of biofilm following exposure to test formulation is expressed as a percentage based on percent reduction between untreated (blank) wells and treated wells using the following equation:

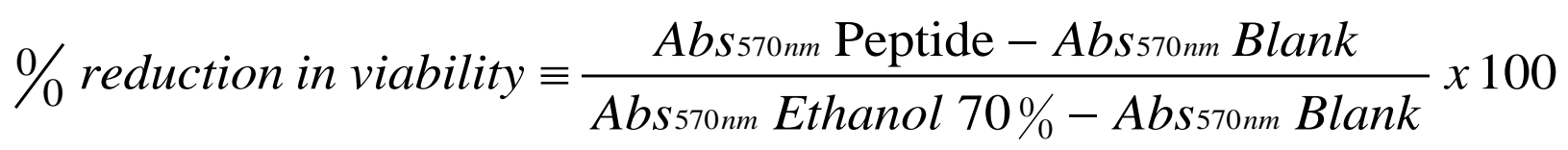

Cell Viability Assay 
Murine fibroblast subcutaneous connective tissue cell line, NCTC Clone 929 (ATCC CCL 1), was cultured in Minimum Essential Medium (MEM) containing phenol red with Earle’s Salts and L-Glutamine, supplemented with 10\% Horse Serum, $100 \mathrm{iu} / \mathrm{mL}$ penicillin and $100 \mu \mathrm{g} / \mathrm{mL}$ streptomycin supplied by Invitrogen (Paisley, UK). Cells were grown at $37^{\circ} \mathrm{C}$ and $5 \% \mathrm{CO}_{2}$ and subcultured at 80 - $90 \%$ confluency. Subculturing consisted of removal of spent medium, rinsing of the adherent cell surface with sterile autoclaved PBS before treatment with a $0.05 \%$ trypsin/0.53 mM EDTA·4Na solution (Invitrogen, Paisley, UK) for cell monolayer detachment. Cell viability was assessed by means of a quantitative alamarBlue ${ }^{\circledR}$ assay, similar to that utilized by O’Brien and colleagues. ${ }^{28}$ Cells were cultured (until at least third passage) and inoculated into 96-well tissue culture treated microtitre plates at a concentration of $1 \times 10^{4}$ cells/well and incubated at $37^{\circ} \mathrm{C}$ and $5 \% \mathrm{CO}_{2}$ for $24 \pm 1$ hour, until approximately 90\% confluency. After this time, the medium was removed and replaced with $100 \mu \mathrm{L}$ of 2.0 1.5, 1.0 and $0.5 \% \mathrm{w} / \mathrm{v}$ NapFF, NapFFKK, NapFFFKK, NapFFOO, NapFFK'K' in separate wells of the microtitre plate and cell monolayers exposed for 24 hours. Absorption was measured at $570 \mathrm{~nm}$ in a Tecan Sunrise ${ }^{\circledR}$ plate reader after a development time of 10 hours. A positive control (100\% reduction in viability) was also included in the assay using 70\% ethanol. The negative control (untreated) consisted of tissue culture cells in $100 \mu \mathrm{L}$ phosphate buffer saline (PBS). Percentage cell viability was calculated relative to untreated control wells as per the biofilm assay above. This value was subtracted from 100 to provide a percentage viability value displayed in Figure 6. 3-0.5\% w/v HPMC controls (Figure S22) displayed no significant reduction of viable fibroblast cells compared to positive controls (no gels), thus confirming the validity of the study.

Hemolysis 
All peptide gels/solutions were assayed spectrophotometrically for their ability to induce hemoglobin release from fresh equine erythrocytes according to the method previously described. ${ }^{21}$ Fresh defibrinated equine erythrocytes were washed three times with equal volumes of PBS. After centrifugation for 15 minutes at $900 \mathrm{~g}$ erythrocytes were resuspended to $4 \% \mathrm{v} / \mathrm{v}$ in PBS. Equal volumes (100 $\mu \mathrm{L})$ of the erythrocyte suspension were added to each well of a 96-well microtitre plate. Erythrocytes were subsequently exposed to peptide concentrations of 2.0-0.5\% $\mathrm{w} / \mathrm{v}$, incubated at $37^{\circ} \mathrm{C}$ for 1 hour and centrifuged at $1000 \mathrm{~g}$. Aliquots of the supernatant were transferred to a fresh 96-well microtitre plate, and hemoglobin release measured spectrophotometrically at $405 \mathrm{~nm}$ (Tecan Sunrise ${ }^{\circledR}$ plate reader). As a positive control $(100 \%$ hemolysis), erythrocytes were treated with $0.1 \%$ Triton X-100, whilst PBS ( $0 \%$ hemolysis) acted as a negative control. All peptide concentrations are reported as the mean of six replicates. Percentage hemolysis was calculated as follows:

$$
\% \text { Hemolysis } \equiv \frac{A b s_{405 n m} \text { Peptide }-A b s_{405 n m} P B S}{A b s_{405 n m} 0.1 \% \text { TritonX }-A b s_{405 n m} P B S} \times 100
$$

\section{Statistical Analysis}

Statistical analyses were performed using GraphPad Prism 6. Standard deviations were obtained at each concentration of peptide tested based on eight replicates for quantitative biofilm viability assays and mean values obtained. For cell cytotoxicity assays standard deviations and mean values were also obtained from eight replicates at each concentration. Statistical analyses were employed using a Kruskal-Wallis test, with a Dunn's multiple comparisons test used to identify individual 
differences between the reduction in biofilm viability for each peptide hydrogel and the positive control ( $0 \%$ reduction). A Kruskal-Wallis test, followed by a Dunn's multiple comparisons test, was also utilized for statistical analysis of tissue culture cytotoxicity data by comparison of percentage viability for the peptides employed to the positive control (100\% viability), with significant reduction in viability reported. Hemolysis data was compared by the same statistical method with percentage hemolysis compared to the PBS, non-hemolytic, control ( $0 \%$ hemolysis). Non parametric Kruskal-Wallis tests were employed rather than parametric Analysis of Variance (ANOVA) as data was shown to be non-normally distributed using the Kolmogorov and Smirnov method. In all cases a probability of $\mathrm{P}<0.05$ denoted significance.

Results and Discussion

Gel Inversion Assay

The ability of the naphthalene peptide derivatives to self-assemble and therefore gel at physiological $\mathrm{pH}$ is determined largely by the intermolecular forces of attraction between the primary structure and the solvent molecules, predominantly water in this case. NapFF has been previously characterized to form a self-supporting gel at concentrations as low as $0.4 \% \mathrm{w} / \mathrm{v}$ in water, due to extensive $\pi$ - $\pi$ interactions between aromatic groups present on the naphthalene and phenylalanine residues. ${ }^{29}$

The presence of two lysine or ornithine residues in the primary sequence confers increased hydrophilic, cationic charge to the molecule thereby increasing the minimum gelation concentration, to $1.0 \% \mathrm{w} / \mathrm{v}$, relative to NapFF (Table 1). The inclusion of three phenylalanine residues increased the overall hydrophobic character of the NapFFFKK molecule compared with 
NapFFKK, however not sufficiently to enable gelation to occur at $0.5 \% \mathrm{w} / \mathrm{v}$ (refer to supplementary information for full set of optical images: Figures S6-S8). The inclusion of an extra phenylalanine group did not appear to have as a significant effect on driving hydrogelation when conjugated to two lysine or ornithine groups. For NapFFK'K', lysine molecules formed peptide bonds to neighboring amino acids via their respective side chain amino (R) group. They are linked molecularly by the epsilon ( $\varepsilon$ ) amino group rather than the standard amino grouping, thus allowing gelation to occur at $0.5 \% \mathrm{w} / \mathrm{v}$ peptide. The inclusion of the R-group amine into an isopeptide bond with the carboxylic acid of phenylalanine may lessen the availability of the free primary amine ($\mathrm{NH}_{2}$ ) on lysine to partake in hydrogen bonding with water, as the carbon tail has been reduced from a butyl amine (- $\left.\mathrm{CH}_{2}-\mathrm{CH}_{2}-\mathrm{CH}_{2}-\mathrm{CH}_{2}-\mathrm{NH}_{2}\right)$ to direct covalent attachment to the $\alpha$-carbon.

Table 1. Minimum gelation concentration (\% w/v) of naphthalene-based peptides

\begin{tabular}{|l|l|}
\hline Peptide & $\begin{array}{l}\text { Minimum gelation concentration of } \\
\text { synthesized peptides (\% w/v) }\end{array}$ \\
\hline NapFF & 0.5 \\
\hline NapFFKK & 1.0 \\
\hline NapFFK'K' & 0.5 \\
\hline NapFFOO & 1.0 \\
\hline NapFFFKK & 1.0 \\
\hline
\end{tabular}



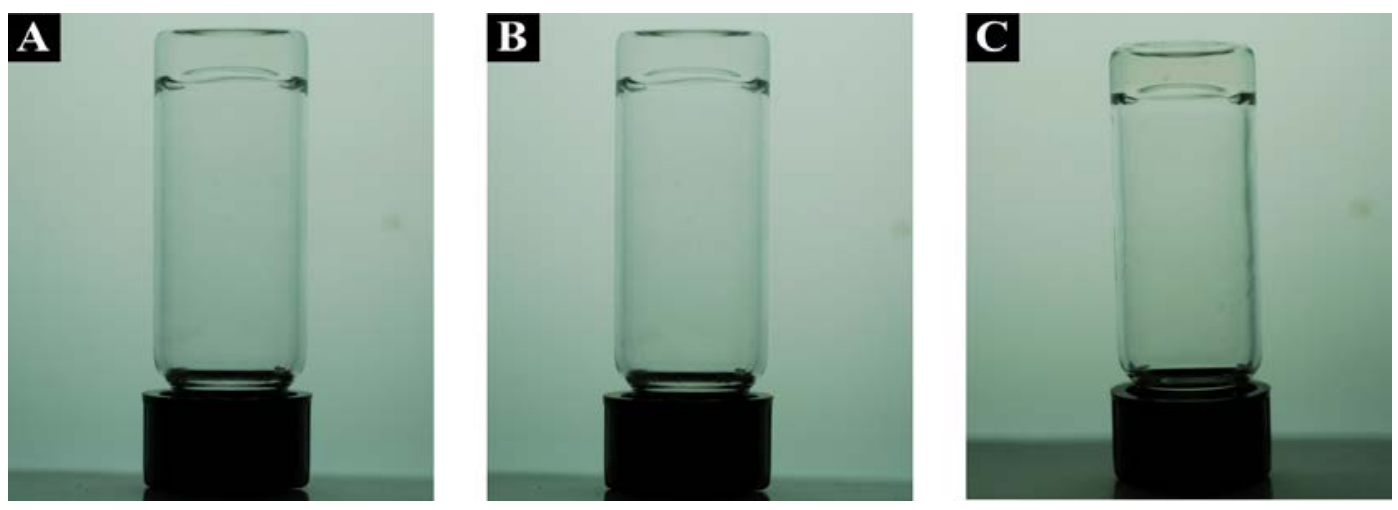

Figure 2. Optical images of gel (A) NapFFOO, (B) NapFFKK, (C) NapFFK’K', at a concentration of $1 \% \mathrm{w} / \mathrm{v}$ and $\mathrm{pH}$ of 7.4 in water

\section{Cryo-SEM, TEM, FTIR and CD Spectroscopy}

The supramolecular hydrogels display random high entanglements of densely packed three dimensional fiber structures as confirmed by cryo-SEM and TEM. Micrographs show that all hydrogels, for the five peptide variants, possess a similar fibrous nature (Figures S9-S12). TEM images for NapFFOO, NapFFKK and NapFFK'K’ (Figure 3) confirm the densely packed nature of these structures and their nanoscale architecture (NapFF TEM images, Figure S13). FTIR spectra (Figure S14) display strong transmittance troughs in the amide I region at approximately $1627 \mathrm{~cm}^{-1}$ and shoulders at $\sim 1570 \mathrm{~cm}^{-1}$. These are indicative of possible $\beta$-sheet secondary structures in the presence of supramolecular hydrogels at $2 \% \mathrm{w} / \mathrm{v}$ peptide. ${ }^{30,31}$ However, the transmittance bands are less pronounced than for other larger peptides studied. ${ }^{32,33}$ There is acknowledgement with the field that contradictory models for molecular structure exist for short self-assembled peptides. ${ }^{16}$ FTIR spectra for polypeptide sequences and proteins, which possess the antiparallel form of $\beta$-sheet conformation, show a characteristic large and sharp trough between 
1615 and $1638 \mathrm{~cm}^{-1}$, attributed to $\beta$-sheet formation. A generally weaker peak at around $1672-$ $1694 \mathrm{~cm}^{-1}$ signifies an antiparallel confirmation. The peptide spectra recorded display quite a different spectral fingerprint, with possible merging of troughs in this area. The wide band stretch to $1650 \mathrm{~cm}^{-1}$ may be misinterpreted as the presence of $\alpha$-helical conformations. ${ }^{34}$ Although it has been well established that the short peptide length, less than 7 amino acids, prevents this conformation. ${ }^{35,36}$ The primary structures of the peptides studied fit with the requirements of a $\beta$ sheet secondary structure, namely; surfaces that are highly polar via side chain groups (lysine, ornithine) and capable of hydrogen bonding, correlating with surfaces that contain nonpolar, hydrophobic side chains (phenylalanine, naphthalene). ${ }^{37}$

The supramolecular arrangement and secondary structure of the peptide hydrogels were confirmed by CD spectroscopy (Figures S15 and S16). The CD spectra display a negative peak at $218 \mathrm{~nm}\left(\mathrm{n}-\pi^{*}\right.$ transition) and a positive peak at $197 \mathrm{~nm}$ (excitation splitting of lowest peptide $\pi$ $\left.\pi^{*}\right)$ at concentrations above the minimum gelation concentration for all peptides. These signals (below $240 \mathrm{~nm}$ : far UV) are similar to the CD signals for $\beta$-sheet polypeptides and confirm the self-assembled peptide backbone predominantly forms a $\beta$-sheet arrangement. $0.5 \% \mathrm{w} / \mathrm{v}$ NapFFKK, NapFFOO and NapFFFKK do not display a corresponding $\beta$-sheet CD spectrum due to an absence of higher ordered structures below the minimum gelation concentration. A less ordered random-coil spectrum is observed for each, with negative and positive bands at 200 nm and $\sim 220 \mathrm{~nm}$ respectively. Broad positive peaks at $\sim 240 \mathrm{~nm}$ are indicative of $\pi-\pi^{*}$ transitions of aromatic phenyl groups. Smaller positive bands at $286 \mathrm{~nm}$ and $296 \mathrm{~nm}$ correspond to $\pi$ - $\pi^{*}$ and n$\pi^{*}$ transitions the naphthalene aromatic group. ${ }^{38}$ The CD spectra are similar to the antiparallel $\beta$ sheet orientation proposed by Adams and co-workers, with $\pi-\pi$ interactions between adjacent naphthalene groups form an extended two-dimensional sheet structure. ${ }^{39}$ Signals indicating $\beta$-sheet 
configuration (transitions at $197 \mathrm{~nm}$ to $218 \mathrm{~nm}$ ) increase in magnitude relative to increased concentration and gel strength (at 2\% w/v: NapFFK'K' $>$ NapFFOO $>$ NapFFKK $>$ NapFFFKK for the cationic naphthalene variants. This corresponds with the observed storage moduli trends (Oscillatory rheology).
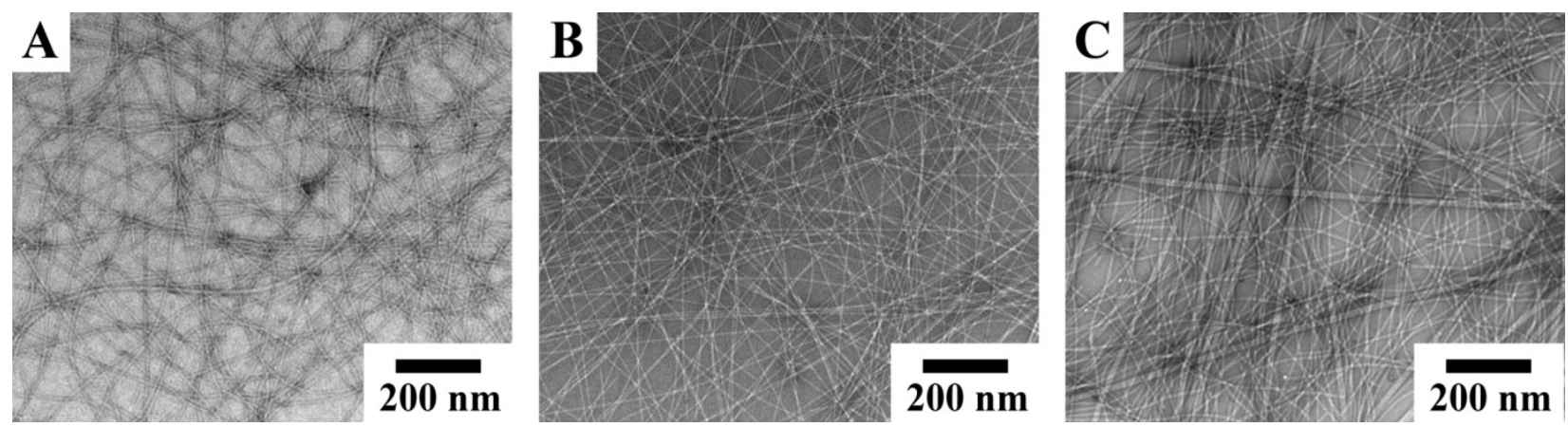

Figure 3. Transmission electron microscopy (TEM) images of (A) NapFFOO, (B) NapFFKK, (C) NapFFK'K', at a concentration of $1 \% \mathrm{w} / \mathrm{v}$ and $\mathrm{pH}$ of 7.4 in water.

Oscillatory Rheology

Frequency sweep analysis (Figures S17b and S18b) confirmed that at 2\% and 1\% w/v naphthalene hydrogels are primarily elastic in nature. For all peptides, the storage modulus (G') was proven to be greater than the loss modulus (G') across a range of frequencies tested within the relevant LVR obtained by oscillatory stress sweeps (Figures S17a and S18a). The naphthalene hydrogels display the mechanical properties of a typical rigid, self-supporting hydrogel with G' values larger than G” by at least an order of magnitude. ${ }^{30}$ Within the LVR the storage and loss moduli of $2 \%$ and $1 \% \mathrm{w} / \mathrm{v}$ hydrogels are relatively constant in the range of frequencies studied. This confirms the presence of a non-covalent cross-linked network of fibers formed by a combination of hydrogen bonding, $\pi-\pi$ stacking and van der Waals' interactions. ${ }^{40,41}$ Comparison 
of the storage moduli for each of the naphthalene peptides demonstrated a large range of gel rigidities. All peptides display a concentration dependent increase in the mean storage modulus (G') as the peptide concentration rises from $1 \%$ to $2 \% \mathrm{w} / \mathrm{v}$. There is also correlation between minimum gelation concentration and G' between peptides. The relative magnitudes of G' at 2\% w/v are ranked as follows: NapFFK'K' (5830 Pa) > NapFFOO (1346 Pa) > NapFFKK (195 Pa) > NapFFFKK (180 Pa) for the cationic naphthalene variants. NapFFK'K' produced the most rigid hydrogel. An increase in rigidity for NapFFK'K' gels may be due to decreased availability of the primary amine to form hydrogen bonds with water compared with standard NapFFKK. Variation in the molecular structure resulted in an increase in G' and a decrease in G', for NapFFK'K', relative to NapFFKK and NapFFOO. This may be attributed to a reduction in the ability of NapFFK'K' to dissolve fully in water to form a solution. Single atom substitutions have been shown previously to significantly affect side chain $\pi-\pi$ interactions on ortho, meta and para positions of phenylated side chains. ${ }^{42}$ It is possible that elongation of the amine conjugated side chain (R-group) in lysine may similarly inhibit the complementary $\pi-\pi$ stacking interactions between neighboring phenyl side chains as the steric bulk of the NapFFKK molecule increases. This was also demonstrated for NapFFFKK as a similar G' (180 Pa) to NapFFKK was observed at $2 \% \mathrm{w} / \mathrm{v}$. Direct covalent attachment of the free amine to the $\alpha$-carbon in the epsilon variant is sterically favorable to drive self-assembly. This was observed by the formation of NapFFK'K' gels at lower concentrations $(0.5 \% \mathrm{w} / \mathrm{v})$ relative to NapFFKK, NapFFOO and NapFFFKK, with more rigid gels obtained at the same concentrations. Tuning rheological properties to the necessary requirements remains one of the greatest challenges in the production of short self-assembling peptide variants. Assembly kinetics and the gelation process are as significant to the overall mechanical properties as molecular structure..$^{43,44}$ 


\section{Biofilm Susceptibility Assay}

The ability of the peptide self-assembled hydrogels to reduce viable biofilm was demonstrated against four key species of bacteria associated with biomaterial related infection: Gram-positive Staphylococcus epidermidis (ATCC 35984) and Staphylococcus aureus (ATCC 29213), and the Gram-negative pathogens Pseudomonas aeruginosa (PAO1) and Escherichia coli (NCTC 11303) (Figures 4, S19, S20 and 5 respectively). ${ }^{45,46}$ Ultrashort naphthalene self-assembled gels containing two lysine residues (NapFFKK and NapFFFKK) displayed the most significant $(\mathrm{P}<0.001)$ antibiofilm activity at the concentrations tested. NapFFKK and NapFFFKK displayed significant reduction $(\mathrm{P}<0.05)$ of biofilm, $87.5 \%$ and $81.25 \%$ respectively, across all four concentrations employed and all four pathogens tested (16 variables in total). 2\% w/v NapFFKK hydrogels were shown to reduce viable biofilm by 94\% against Staphylococcus epidermidis, with 2\% w/v NapFFFKK demonstrating $85 \%$ reduction. The addition of an extra phenylalanine does not adversely affect either gelation (minimum gelation retained at $1 \% \mathrm{w} / \mathrm{v}$ : no visible precipitation occurred) or antibiofilm activity. By comparison NapFFK'K' gels showed no significant antibiofilm activity at any of the variables ( 4 concentrations and 4 pathogens) analyzed. The major difference in the structure of NapFFKK and NapFFK'K' is the length of the methyl chain on the lysine R-group. We hypothesize that modification of the methylene chain, from a butyl amine to direct covalent attachment on the $\alpha$-carbon, has reduced the antibiofilm activity of the NapFFK'K' peptide. This theory is further supported by the data obtained for NapFFOO. Ornithine has one less methylene unit (forming a propyl amine) on its R-group than lysine. This subtle molecular difference has little effect on the gelation ability of the two respective peptides (Table 1: both 1.0\% w/v) but it does have a significant effect on antibiofilm activity. The primary amine of the R- 
group tail is not as readily available to interact with the negatively charged bacterial membrane and its constituent acidic molecules including: acidic hydroxylated phospholipids such as cardiolipin, phosphatidylglycerol and phosphatidylserine; lipopolysaccharides; and teichoic acid. This is a key parameter of antimicrobial peptide activity. ${ }^{19}$

It has been previously established that a minimum of two charged and two hydrophobic amino acid units are required to confer antimicrobial activity to ultrashort peptide variants, providing validation to the primary structures we have selected. ${ }^{47}$ NapFF displays significant reduction in viable biofilm at concentrations of $1.5 \% \mathrm{w} / \mathrm{v}$ and above against Staphylococcus epidermidis, Escherichia coli and Pseudomonas aeruginosa. This is likely due to hydrophobic interactions and detergent-like effects with bacterial membranes at higher concentrations. The addition of charged moieties increases the antibiofilm activity of the NapFF molecule, with the exception of NapFFK'K'. The addition of K'K' may have resulted in a sub-optimal hydrophobic: charge balance in the molecule, thereby decreasing interaction with bacterial membranes and reducing antimicrobial activity.

NapFFFKK is the only peptide hydrogel to display significant activity against Staphylococcus epidermidis (ATCC 35984) at both 1 and $0.5 \% \mathrm{w} / \mathrm{v}$. This phenomenon can be explained by an increase in the hydrophobicity of NapFFFKK relative to NapFFKK. The inclusion of a single phenylalanine has allowed an optimum hydrophobic: charge balance to be obtained. ${ }^{19}$ Therefore NapFFFKK is able to penetrate and eradicate Staphylococcus epidermidis (ATCC 35984) biofilm at lower concentrations. NapFF does not have sufficient cationic charge or hydrophobicity at the lower concentrations to induce biofilm eradication. Greater biofilm eradication occurs in Grampositive Staphylococcus aureus (ATCC 29213) relative to Staphylococcus epidermidis (ATCC 35984) for all peptides due to differences in the biofilm architecture of the two isolates of Gram- 
positive bacteria employed. Staphylococcus epidermidis (ATCC 35984) forms a notoriously thick biofilm matrix that retards the penetration of a multitude of antibiotics. Staphylococcus aureus (ATCC 29213) also forms a thick biofilm but it is relatively fragile by comparison; as confirmed by Di Stefano. ${ }^{48}$ Lysine is able to penetrate the thick biofilm matrix of Staphylococcus epidermidis (ATCC 35984), to a greater extent than ornithine based peptides by attacking its membrane architecture. This is due to the increased availability of the free primary amine. NapFFKK does not have sufficient hydrophobic character to cause significant reduction of Staphylococcus epidermidis biofilm at lower concentrations $(\leq 1 \% \mathrm{w} / \mathrm{v})$.

A trend of increasing antibiofilm activity is apparent relative to increasing concentration for NapFF, NapFFKK, NapFFOO and NapFFFKK irrespective of whether self-assembly has occurred. Therefore if antimicrobial activity cannot be conclusively linked to the process of selfassembly, the possibility exists that antimicrobial activity may be due in part to the presence of soluble cationic peptide in the area surrounding the hydrogel surface.

Research by Salick and colleagues similarly debated this issue. ${ }^{49}$ They showed the higher molecular weight, 20 residue, MAX1 hydrogel to display an inherently antimicrobial surface. Similar to our ultrashort derivatives gelation occurred at greater than $0.5 \% \mathrm{w} / \mathrm{v}$, indicating that the soluble aggregates are likely to be the most active species as bacterial proliferation in the presence of lower levels of soluble MAX1 was comparable to bacterial samples with no peptide. The surface structure of MAX1 is similar to NapFFKK, NapFFOO and NapFFFKK, with a polycationic lysine-rich face that may be responsible for broad-spectrum antibacterial activity. The Schneider group utilized this knowledge and the MAX1 template to produce second generation cationic self-assembly hydrogels possessing both arginine and lysine. MARG1, containing two arginine residues, was highly active against methicillin resistant Staphylococcus 
aureus, whilst PEP6R, containing six arginines, demonstrated a broad spectrum of activity against Staphylococcus aureus, Escherichia coli and Pseudomonas aeruginosa. ${ }^{50,51}$

Similarly our self-assembled hydrogels are composed of a hydrophobic naphthalene and phenylalanine core with cationic ornithine and lysine exteriors, at a reduced peptide length and cost. In the fibrous hydrogel form the cationic amino acids are available to displace divalent metal ions from the bacterial cell well causing membrane disruption in biofilm cells and leading to cell death in both Gram-positive and -negative pathogens. ${ }^{52}$ The successful reduction achieved by our ultrashort cationic peptide hydrogels in the more resistant biofilm phenotype of bacteria is important for translating these molecules into biomaterial and biomedical therapies as these are the primary causative phenotype in medical device related infection. ${ }^{53}$

The diphenylalanine motif has demonstrated previous success as an antimicrobial selfassembled carrier molecule. Paladini and colleagues created a silver-doped self-assembling 9fluorenyl-methoxycarbonyl (Fmoc) derivative (Fmoc-FF) wound dressing. This demonstrated 99\% inhibition of the planktonic Staphylococcus aureus phenotype when 2\% silver nanoparticles were incorporated into the hydrogel matrix and coated onto flax. ${ }^{54}$ Debnath et al, utilized Fmocbased amphiphiles with cationic moieties allowing for broad spectrum antibacterial activity against less resistant planktonic forms of Gram-positive and -negative bacteria, including Staphylococcus aureus, Escherichia coli and Pseudomonas aeruginosa. ${ }^{33}$ Self-assembled peptides have high potential for wound dressings, biomaterials and other biomedical applications due to their fibrous architecture and high water content, mimicking the extracellular matrix and promoting healing. ${ }^{55}$ Our ultrashort cationic naphthalene derivatives have the extra advantage of inherent antimicrobial activity for the prevention of infection. 


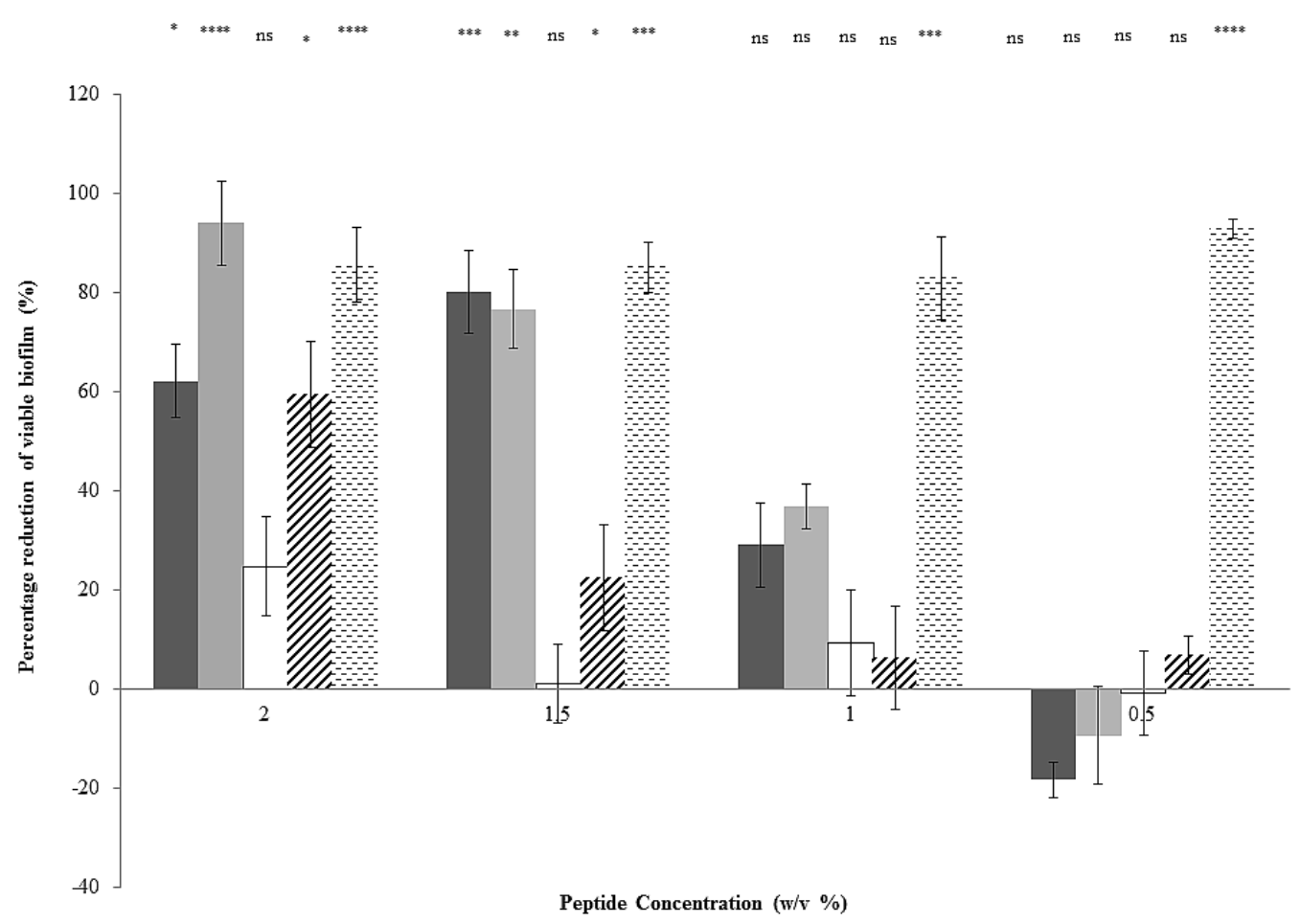

Figure 4. Percentage reduction of mature 24 hour Staphylococcus epidermidis (ATCC 35984) biofilm after 24 hour incubation with naphthalene derived self-assembled hydrogels utilizing an alamarBlue ${ }^{\circledR}$ assay. Results are displayed as a mean of 8 replicates. Key:

\section{NapFF $\quad$ NapFFKK $\quad \square$ NapFFK'K' "NapFFOO $\therefore$ NapFFFKK}

NS: no significant difference $(\mathrm{P} \geq 0.05)$, *: $\mathrm{P}<0.05$, **: $\mathrm{P}<0.01$, ***: $\mathrm{P}<0.001, * * * *: \mathrm{P}<0.0001$ significant difference between Log10CFU/mL of peptide and the positive control (no peptide). 

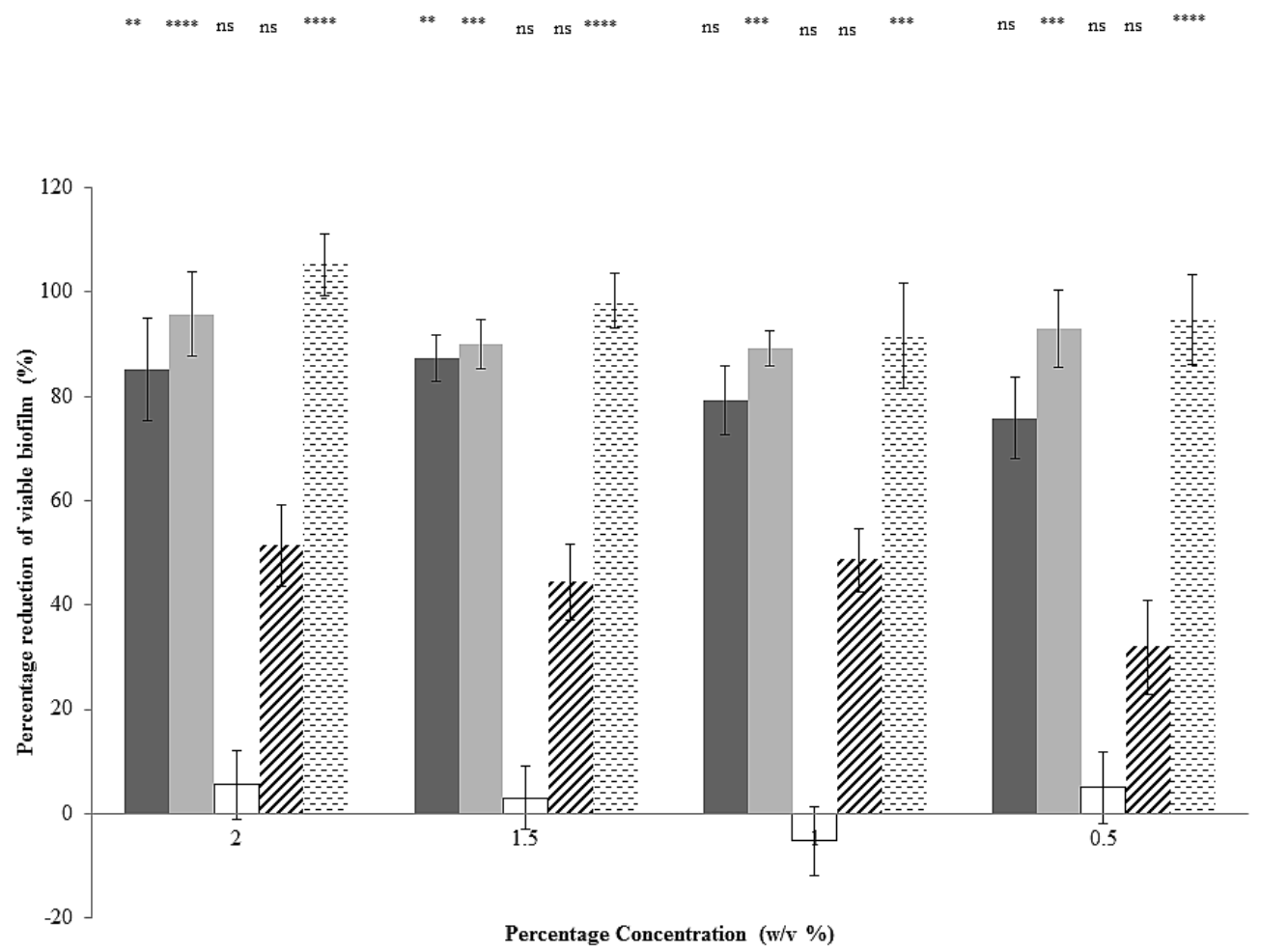

Figure 5. Percentage reduction of mature 24 hour Escherichia coli (NCTC 11303) biofilm after 24 hour incubation with naphthalene derived self-assembled hydrogels utilizing an alamarBlue ${ }^{\circledR}$ assay. Results are displayed as a mean of 8 replicates. Key:

NapFF $\quad$ NapFFKK $\quad \square$ NapFFK'K' "NapFFOO $\quad \therefore$ NapFFFKK

NS: no significant difference ( $\mathrm{P} \geq 0.05)$, *: $\mathrm{P}<0.05$, **: $\mathrm{P}<0.01, * * *$ : $\mathrm{P}<0.001, * * * *$ : $\mathrm{P}<0.0001$ significant difference between $\log _{10} \mathrm{CFU} / \mathrm{mL}$ of peptide and the positive control (no peptide). 
Cell Viability and Hemolysis

The cytotoxicity of cationic naphthalene based peptides was evaluated against the International Standard cytotoxicity cell line CCL 1 . The results obtained (Figure 6) show reduced cell toxicity in comparison to bacterial biofilm cells. Comparison of the results for all five peptides at the four concentrations employed against the CCL 1 cell line show significant $(\mathrm{P}<0.05)$ reduction in cell viability in under half of the samples tested (9 out of 20: 45\%). The most successful antibiofilm molecule, NapFFKK, is particularly cytotoxic displaying a significant reduction in viability at all concentrations tested. NapFFK'K’ possesses the greatest cytocompatibility, with no significant toxicity demonstrated against murine fibroblasts, similar to activity against bacterial isolates. NapFF was previously found to show greater than $90 \%$ viability at $200 \mu \mathrm{M}$ against HeLa cells. ${ }^{13}$ Naphthalene was purposely chosen as a phenyl substituent due to its established safety profile. It is utilized in many current pharmaceutical formulations including propranolol, naphazoline and nafronyl. ${ }^{56}$

A relative reduction in activity against mammalian cells may be attributed to a neutral zwitterionic eukaryotic cell membrane due to the high proportion of phospatidylcholine, phosphatidylethanolamine, sphingomyelin, sterols, cholesterol and ergosterol. ${ }^{57}$ Therefore cationic peptides possess reduced selectivity for mammalian membranes, compared with negatively charged bacterial forms, as demonstrated previously by our group. ${ }^{21}$

Further insight into the selectivity of our peptides for mammalian membranes was obtained via a hemolysis assay with results displayed in Figure 7. Only NapFF and NapFFFKK displayed significant $(\mathrm{P}<0.05)$ hemolytic activity at the highest $(2 \% \mathrm{w} / \mathrm{v})$ concentrations employed. This may be due to predominantly hydrophobic interaction with neutral erythrocyte cell membranes. All samples tested had a value of $15 \%$ hemolysis or less indicating the eukaryotic cell surface is 
intact and that the majority of peptides are non-hemolytic. No conclusive correlation was found between the degree of hemolysis and peptide gelation.

The creation of stimuli-responsive molecules may further improve the selectivity of these peptides for bacterial pathogens. For example, the Ulijn group synthesized a variety of Fmoc dipeptide amphiphiles that demonstrated enzyme responsive antibacterial activity and gelation in the presence of alkaline phosphate producing Escherichia coli. ${ }^{58}$ Bacterial proteases, such as sortase, could provide valid targets for specific infections, in this case staphylocococci. ${ }^{59}$ Other environmental stimuli that could be harnessed include modification of the $\mathrm{pH}$ switch used to control the process of self-assembly in our hydrogels. Urinary catheter infections associated with Proteus mirabilis display an increased $\mathrm{pH}$ clinically. Therefore reversing assembly to occur at high $\mathrm{pH}$, via alteration of the primary amino acid sequence, may prove beneficial in such infections. ${ }^{60}$

The antimicrobial motifs have the potential to be conjugated directly to the surface of medical devices. Peptides have the flexibility to be conjugated to biomaterials with precision. Methods for attachment include grafting via peptide reactive polymers such as polyethylene glycol and $\mathrm{N}$ (2-hydroxypropyl)methacrylamide. ${ }^{61}$ Successful translation of self-assembled peptides into therapeutics is provided by the example of Lanreotide growth inhibitor. ${ }^{62}$ Self-assembly of this octapeptide occurs via hydrophobic and aromatic interaction, a mechanism similar to our naphthalene variants. As a somatostatin analogue, it is indicated for growth hormone-secreting tumors, displaying prolonged action and an increased half-life. ${ }^{63}$ Lanreotide provides significant promise to the development and future use of self-assembling peptides as pharmaceuticals. 


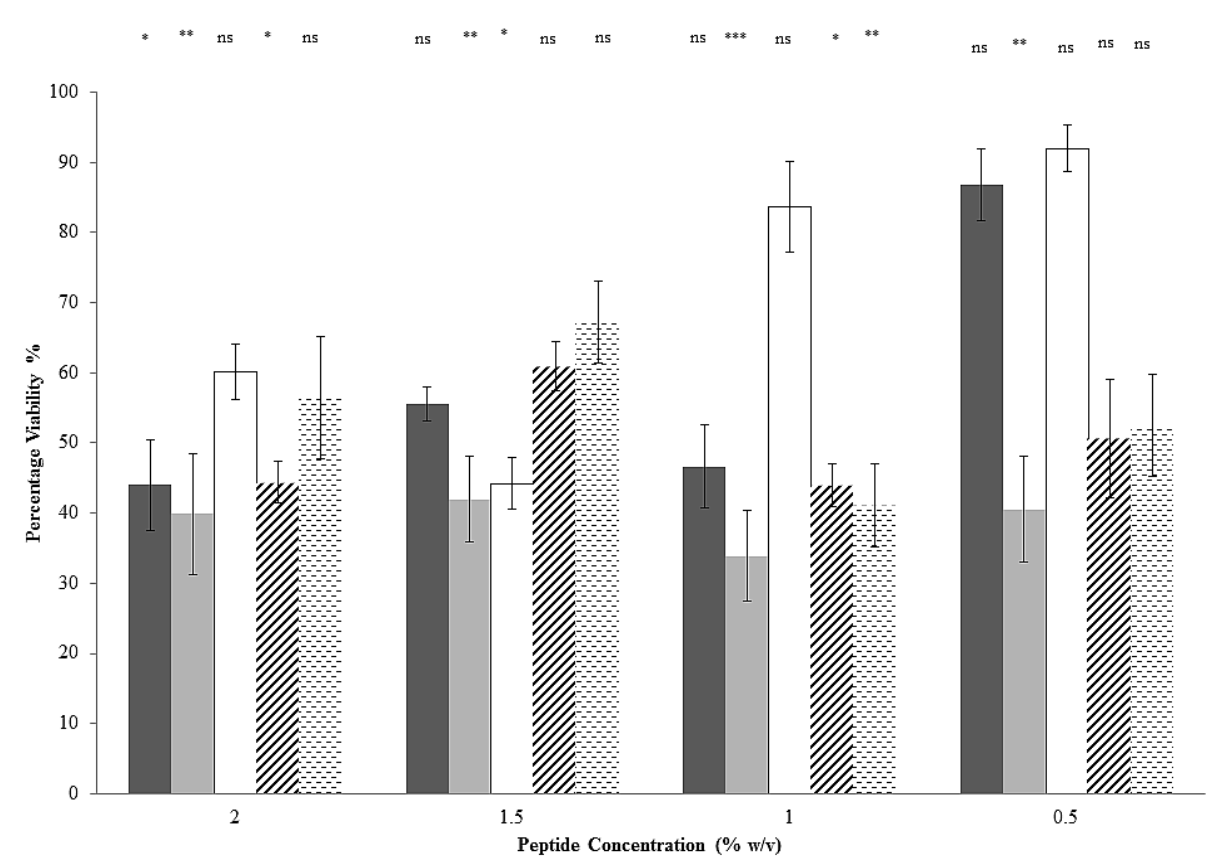

Figure 6. Percentage viability of CCL 1 [NCTC clone 929]- murine fibroblasts subcutaneous connective tissue monolayer cells after 24 hour exposure to naphthalene derived self-assembled hydrogels utilizing an alamarBlue ${ }^{\circledR}$ assay. Results are displayed as a mean of 8 replicates. Key:

napFF $\quad$ NapFFKK $\square$ NapFFK'K' 'NapFFOO $\quad$ NapFFFKK

NS: no significant difference $(\mathrm{P} \geq 0.05)$, *: $\mathrm{P}<0.05$, **: $\mathrm{P}<0.01, * * *$ : $\mathrm{P}<0.001, * * * *: \mathrm{P}<0.0001$ significant difference between $\log _{10} \mathrm{CFU} / \mathrm{mL}$ of peptide and the positive control (no peptide). 


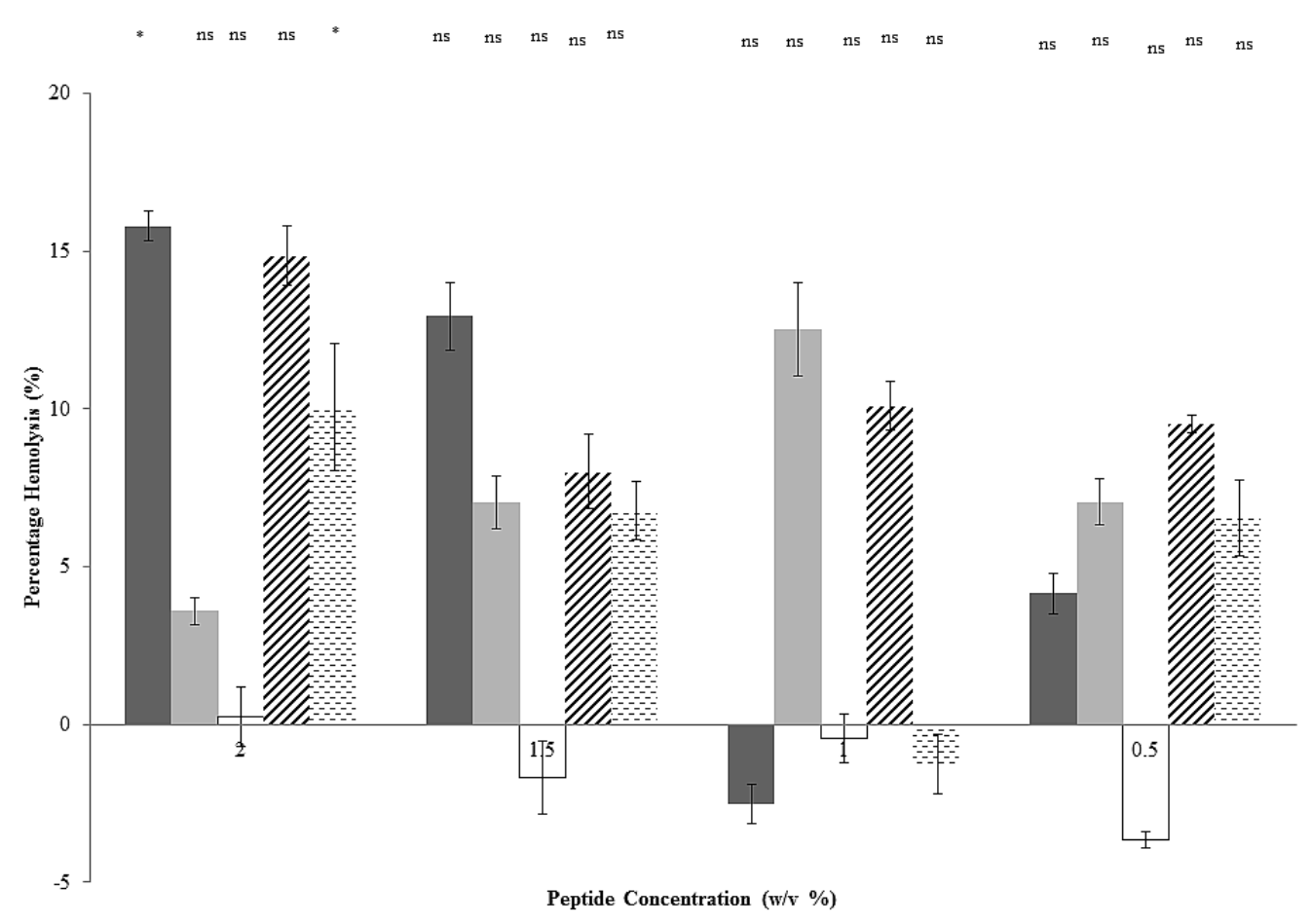

Figure 7. Percentage hemolysis of the naphthalene peptides against equine erythrocytes. Each value is expressed as the mean of six replicates, incubated at $37^{\circ} \mathrm{C}$ for 1 hour. Key:

\section{$\square$ NapFF $\quad$ NapFFKK $\square$ NapFFK'K' 'NapFFOO $\quad \therefore$ NapFFFKK}

NS: no significant difference ( $\mathrm{P} \geq 0.05),{ }^{*}: \mathrm{P}<0.05, * *$ : $\mathrm{P}<0.01, * * *$ : $\mathrm{P}<0.001, * * * *: \mathrm{P}<0.0001$ significant difference between $\log _{10} \mathrm{CFU} / \mathrm{mL}$ of peptide and the positive control (no peptide).

\section{Conclusions}

In this study we explored the in vitro antibacterial properties of ultrashort cationic naphthalene peptides against the more resistant biofilm bacterial phenotype associated with implant related infections. The peptide backbone allows for tunable structural and chemical characteristics based 
on amino acid selection. The use of ultrashort variants has high potential for biomedical development compared with larger peptides and proteins due to reduced cost of production and ease of synthesis, without a reduction in function. We found that the composition of the amino acid R-group significantly influenced antibiofilm properties but not gelation propensity for these peptides. The nanofiber structure of these supramoleular hydrogels were confirmed using cryoSEM and TEM microscopy. Antibiofilm activity tended to increase with increasing peptide concentration. Greater selectivity was shown against biofilm bacteria compared with mammalian cells for these cationic peptides. The lysine containing ultrashort cationic naphthalene peptides show particular promise in eradicating biofilm forms of medical device related pathogens. Further research is required to permit gelation and antimicrobial activity in response to the development of bacterial environmental stimuli in vivo, utilizing factors such as $\mathrm{pH}$, enzymatic and molecular recognition. Thus ensuring antimicrobial activity occurs when it is most required and limiting side effects to patients. The research presented in this paper has fundamental implications for the design and development of innovative biomaterials, tissue scaffolds and drug delivery systems based on the ultrashort cationic naphthalene peptide motif.

Supporting Information Available

${ }^{1} \mathrm{H}$ NMR and ESI MS data (Figures S1-S5); Gel Inversion Images (Figures S6-S8); cryo-SEM Images (Figures S9-S12); TEM images (NapFF) (Figure S13); FTIR (Figure S14); CD spectra (Figures S15 and S16); Oscillatory rheology 2\% w/v and 1\% w/v hydrogels (Figures S17 and S18); Staphylococcus aureus (ATCC 29213) Biofilm Susceptibility assay (Figure S19); Pseudomonas aeruginosa (PAO1) Biofilm Susceptibility assay (Figure S20); 3-0.5\% w/v HPMC Biofilm 
Susceptibility assay (Figure S21); 3-0.5\% w/v HPMC Murine Fibroblast Cell Viability Assay

(Figure S22). This material is available free of charge via the Internet at http://pubs.acs.org

\section{AUTHOR INFORMATION}

\section{Corresponding Author}

*Dr Garry Laverty

Lecturer in Pharmaceutical Science

School of Pharmacy

Medical Biology Centre

Queen’s University Belfast

97 Lisburn Rd

Belfast

BT9 7BL

Tel: +44 (0) 2890972273

Email: garry.laverty@qub.ac.uk 


\section{Author Contributions}

The manuscript was written through contributions of all authors. All authors have given approval to the final version of the manuscript. $¥$ These authors contributed equally.

\section{Notes}

The authors declare no competing financial interest.

\section{ACKNOWLEDGMENT}

The authors acknowledge funding provided by the Queen's University Research Support Package for New Academic Staff for GL and a DEL studentship grant for AMC. We acknowledge the help from Daniel Corbett, Tao Yu and Dr Marie Migaud (all QUB) with their guidance with regard to cryo-SEM, rheological and NMR methodology respectively.

\footnotetext{
ABBREVIATIONS

Boc, tert-Butyloxycarbonyl; $\mathrm{CD}$, circular dichroism; $\mathrm{CFU} / \mathrm{mL}$, colony forming units per milliter; Cryo-SEM, cryo-scanning electron microscopy; $\mathrm{D}_{2} \mathrm{O}$, deuterated water; DMF, dimethylformamide; $\varepsilon$, epsilon; F, phenylalanine; Fmoc, 9-fluorenylmethoxycarbonyl; G', storage modulus; G”, loss modulus; HBTU, 1-H-benzotriazolium; HPMC, hydroxyl propyl methyl cellulose; K, lysine; K', epsilon lysine variant; LVR, linear viscoelastic region; MEM, minimum essential media; MHB, Muellar Hinton broth, Nap, naphthalene; O, ornithine; PBS, phosphate buffered saline.
} 


\section{REFERENCES}

1. Karp, J. M.; Langer, R. Curr. Opin. Biotechnol. 2007, 18, 454-459.

2. Zhang, L.; Cao, Z.; Bai, T.; Carr, L.; Ella-Menye, J. R.; Irvin, C.; Ratner, B. D.; Jiang, S. Nat. Biotechnol. 2013, 31, 553-556.

3. Turner, A. P. Chem. Soc. Rev. 2013, 42, 3184-3196.

4. Elbert, D. L. Curr. Opin. Biotechnol. 2011, 22, 674-680.

5. Boateng, J. S.; Matthews, K. H.; Stevens, H. N.; Eccleston, G. M. J. Pharm. Sci. 2008, 97, 2892-2923.

6. Guvendiren, M.; Lu, H. D.; Burdick, J. A. Soft matter 2011, 8, 260-272.

7. Laverty, G.; Gorman, S. P.; Gilmore, B. F. J. Biomed. Mater. Res. A. 2012, 100, 1803-1814.

8. Davies, D. Nat. Rev. Drug Discov. 2003, 2, 114-122.

9. Stone, P. W. Expert Rev. Pharmacoecon Outcomes Res. 2009, 9, 417-422.

10. Mart, R. J.; Osborne, R. D.; Stevens, M. M.; Ulijn, R. V. Soft Matter 2006, 2, 822-835.

11. Altunbas, A.; Lee, S. J.; Rajasekaran, S. A.; Schneider, J. P.; Pochan, D. J. Biomaterials 2011, 32, 5906-5914.

12. Ulijn, R. V.; Smith, A. M. Chem. Soc. Rev. 2008, 37, 664-675.

13. Yang, Z.; Liang, G.; Ma, M.; Gao, Y.; Xu, B. J. Mater. Chem 2007, 17, 850-854. 
14. Zhou, M.; Smith, A. M.; Das, A. K.; Hodson, N. W.; Collins, R. F.; Ulijn, R. V.; Gough, J. E. Biomaterials 2009, 30, 2523-2530.

15. Reches, M.; Gazit, E. Science 2003, 300, 625-627.

16. Ryan, D. M.; Nilsson, B. L. Polym. Chem. 2012, 3, 18-33.

17. Dasgupta, A.; Mondal, J. H.; Das, D. RSC Advances. 2013, 3, 9117-9149.

18. Guler, M. O.; Hsu, L.; Soukasene, S.; Harrington, D. A.; Hulvat, J. F.; Stupp, S. I. Biomacromolecules 2006, 7, 1855-1863.

19. Laverty, G.; Gorman, S. P.; Gilmore, B. F. Int. J. Mol. Sci. 2011, 12, 6566-6596.

20. Siddique, B.; Duhamel, J. Langmuir 2011, 27, 6639-6650.

21. Laverty, G.; McLaughlin, M.; Shaw, C.; Gorman, S. P.; Gilmore, B. F. Chem. Biol. Drug Des. 2010, 75, 563-569.

22. Adams, D. J.; Butler, M. F.; Frith, W. J.; Kirkland, M.; Mullen, L.; Sanderson, P. Soft Matter 2009, 5, 1856-1862.

23. Pogorelov, A. G.; Selezneva, I. I. Bull. Exp. Biol. Med. 2010, 150, 153-156.

24. Li, J.; Gao, Y.; Kuang, Y.; Shi, J.; Du, X.; Zhou, J.; Wang, H.; Yang, Z.; Xu, B. J. Am. Chem. Soc. 2013, 135, 9907-9914.

25. Castelletto, V.; Hamley, I. W. Biophys. Chem. 2009, 141, 169-174.

26. Pettit, R. K.; Weber, C. A.; Pettit, G. R. Ann. Clin. Microbiol. Antimicrob. 2009, 8, 28. 
27. Paquette, D. W.; Waters, G. S.; Stefanidou, V. L.; Lawrence, H. P.; Friden, P. M.; O'Connor, S. M.; Sperati, J. D.; Oppenheim, F. G.; Hutchens, L. H.; Williams, R. C. J. Clin. Periodontol. 1997, 24, 216-222.

28. O'Brien, J.; Wilson, I.; Orton, T.; Pognan, F. Eur. J. Biochem. 2000, 267, 5421-5426.

29. Zhang, Y.; Kuang, Y.; Gao, Y.; Xu, B. Langmuir 2011, 27, 529-537.

30. Bowerman, C. J.; Ryan, D. M.; Nissan, D. A.; Nilsson, B. L. Mol. Biosyst 2009, 5, 10581069.

31. Jayawarna, V.; Richardson, S. M.; Hirst, A. R.; Hodson, N. W.; Saiani, A.; Gough, J. E.; Ulijn, R. V. Acta Biomater. 2009, 5, 934-943.

32. Schneider, J. P.; Pochan, D. J.; Ozbas, B.; Rajagopal, K.; Pakstis, L.; Kretsinger, J. J. Am. Chem. Soc. 2002, 124, 15030-15037.

33. Debnath, S.; Shome, A.; Das, D.; Das, P. K. J Phys Chem B 2010, 114, 4407-4415.

32. Smith, A. M.; Williams, R. J.; Tang, C.; Coppo, P.; Collins, R. F.; Turner, M. L.; Saiani, A.; Ulijn, R. V. Adv. Mater. Weinheim 2008, 20, 37-41.

33. Cheng, G.; Castelletto, V.; Moulton, C. M.; Newby, G. E.; Hamley, I. W. Langmuir 2010, 26, 4990-4998.

34. Kong, J.; Yu, S. Acta Biochim. Biophys. Sin. (Shanghai). 2007, 39, 549-559.

35. Smith, A. M.; Williams, R. J.; Tang, C.; Coppo, P.; Collins, R. F.; Turner, M. L.; Saiani, A.; Ulijn, R. V. Adv. Mater. Weinheim. 2008, 20, 37-41. 
36. Cheng, G.; Castelletto, V.; Moulton, C. M.; Newby, G. E.; Hamley, I. W. Langmuir. 2010, 26, 4990-4998.

37. Rotondi, K. S.; Gierasch, L. M. Biopolymers 2006, 84, 13-22.

38. Sreerama, N.; Woody, R. W. In Circular dichroism of peptides and proteins; Berova, N., Nakanishi, K. and Woody, R. W., Eds.; Circular dichroism: principles and applications; WileyBlackwell: New York, 2000; pp 601-620.

39. Adams, D. J.; Morris, K.; Chen, L.; Serpell, L. C.; Bacsa, J.; Day, G. M. Soft Matter. 2010, 6, 4144-4156.

40. Yao, S.; Beginn, U.; Gress, T.; Lysetska, M.; Wurthner, F. J. Am. Chem. Soc. 2004, 126, 8336-8348.

41. Haines, L. A.; Rajagopal, K.; Ozbas, B.; Salick, D. A.; Pochan, D. J.; Schneider, J. P. J. Am. Chem. Soc. 2005, 127, 17025-17029.

42. Ryan, D. M.; Anderson, S. B.; Nilsson, B. L. T. Soft Matter. 2010 2010, 6, 3220-3231.

43. George, M.; Weiss, R. G. Acc. Chem. Res. 2006, 39, 489-497.

44. Wang, H.; Yang, Z.; Adams, D. J. Materials Today 2012, 15, 500-507.

45. McCann, M. T.; Gilmore, B. F.; Gorman, S. P. J. Pharm. Pharmacol. 2008, 60, 1551-1571.

46. Danese, P. N. Chem. Biol. 2002, 9, 873-880.

47. Strom, M. B.; Haug, B. E.; Skar, M. L.; Stensen, W.; Stiberg, T.; Svendsen, J. S. J. Med. Chem. 2003, 46, 1567-1570. 
48. Di Stefano, A.; D'Aurizio, E.; Trubiani, O.; Grande, R.; Di Campli, E.; Di Giulio, M.; Di Bartolomeo, S.; Sozio, P.; Iannitelli, A.; Nostro, A.; Cellini, L. Microb. Biotechnol. 2009, 2, 634641.

49. Salick, D. A.; Kretsinger, J. K.; Pochan, D. J.; Schneider, J. P. J. Am. Chem. Soc. 2007, 129, 14793-14799.

50. Salick, D. A.; Pochan, D. J.; Schneider, J. P. Adv. Mater. 2009, 21, 4120-4123.

51. Veiga, A. S.; Sinthuvanich, C.; Gaspar, D.; Franquelim, H. G.; Castanho, M. A.; Schneider, J. P. Biomaterials 2012, 33, 8907-8916.

52. Veiga, A. S.; Schneider, J. P. Biopolymers 2013, 100, 637-644.

53. Francolini, I.; Donelli, G. FEMS Immunol. Med. Microbiol. 2010, 59, 227-238.

54. Paladini, F.; Meikle, S. T.; Cooper, I. R.; Lacey, J.; Perugini, V.; Santin, M. J. Mater. Sci. Mater. Med. 2013, 24, 2461-2472.

55. Schneider, A.; Garlick, J. A.; Egles, C. PLoS One 2008, 3, e1410.

56. Yang, Z.; Liang, G.; Wang, L.; Xu, B. J. Am. Chem. Soc. 2006, 128, 3038-3043.

57. Glukhov, E.; Stark, M.; Burrows, L. L.; Deber, C. M. J. Biol. Chem. 2005, 280, 33960-33967.

58. Hughes, M.; Debnath, S.; Knapp, C. W.; Ulijn, R. V. Biomater. Sci. 2013, 1, 1138-1142.

59. Piluso, S.; Cassell, H. C.; Gibbons, J. L.; Waller, T. E.; Plant, N. J.; Miller, A. F.; Cavalli, G. Soft Matter 2013, 9, 6752-6756.

60. Stickler, D. J.; Morgan, S. D. J. Med. Microbiol. 2006, 55, 489-494. 
61. Shu, J. Y.; Panganiban, B.; Xu, T. Annu. Rev. Phys. Chem. 2013, 64, 631-657.

62. Valery, C.; Paternostre, M.; Robert, B.; Gulik-Krzywicki, T.; Narayanan, T.; Dedieu, J. C.; Keller, G.; Torres, M. L.; Cherif-Cheikh, R.; Calvo, P.; Artzner, F. Proc. Natl. Acad. Sci. U. S. A. 2003, 100, 10258-10262.

63. Roelfsema, F.; Biermasz, N. R.; Pereira, A. M.; Romijn, J. A. Biologics 2008, 2, 463-479.

Table of Contents Graphic

For Table of Contents Only

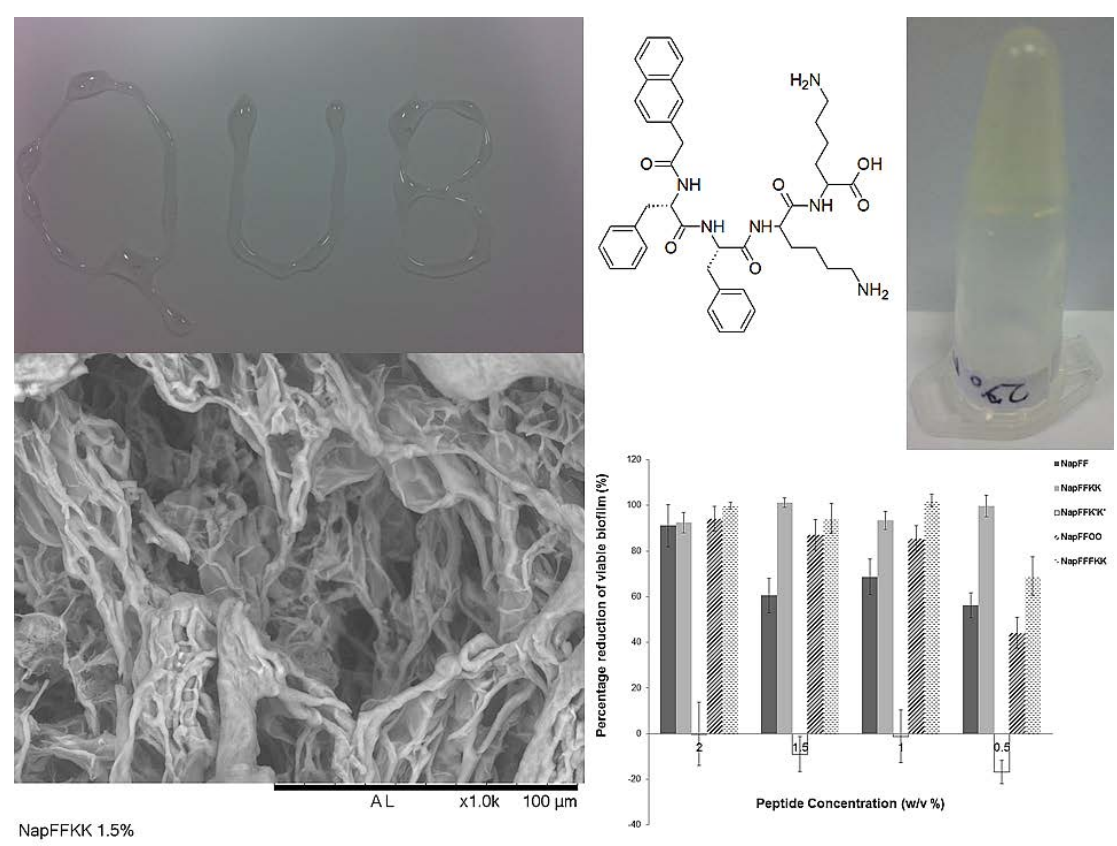

